\title{
Commentary: Unlocking the enigma of neurobehavioral abnormalities after surgery for congenital heart disease
}

\author{
Christian Pizarro, MD
}

From the Nemours Cardiac Center, Alfred I Dupont Hospital, Wilmington, Del.

Disclosures: Author has nothing to disclose with regard to commercial support.

Received for publication Sept 1, 2019; revisions received Sept 1, 2019; accepted for publication Sept 3, 2019; available ahead of print Oct 18, 2019.

Address for reprints: Christian Pizarro, MD, Nemours Cardiac Center, Alfred I Dupont Hospital, 1600 Rockland Rd, Wilmington, DE 19803 (E-mail: Christian.Pizarro@nemours.org).

J Thorac Cardiovasc Surg 2020;159:280-1

$0022-5223 / \$ 36.00$

Copyright (C) 2019 Published by Elsevier Inc. on behalf of The American Association for Thoracic Surgery

https://doi.org/10.1016/j.jtcvs.2019.09.003

With mortality rates decreasing due to advances in surgical and perioperative care of patients with congenital heart disease (CHD), the focus has shifted from survival to functional outcomes, in particular neurobehavioral function. Although it has been well established that young children undergoing interventions to treat CHD are at risk for neurodevelopmental issues, important gaps in knowledge limit our understanding of the etiologic mechanisms and therefore our ability to mitigate or prevent such issues. The Boston Circulatory Arrest Study represents the first effort to determine best practices aimed to understand the potential effect of operative strategies and improve neurodevelopmental outcomes. ${ }^{1}$ On the basis of the findings, significant attention was paid to perfusion strategies during a very narrow window in the episode of care. However, despite some modifications in perfusion practice, no effect on neurobehavioral outcomes was shown. Moreover, a follow-up study of this cohort showed that regardless of the strategy chosen, the outcomes were not too dissimilar. More importantly it seemed that each perfusion strategy was associated with specific neurobehavioral issues, which set these patients apart from other children. ${ }^{2}$

The notion that certain types of CHD can be associated with preexisting neurological lesions has been well documented in the recent era, supporting the notion that there is a lot more to neurodevelopmental outcomes than the mode of circulatory support during surgery. The presence of periventricular leukomalacia or stroke before any intervention speak to the fact that perhaps abnormal circulatory patterns, with or without hypoxia, could play a significant role in the genesis of neurobehavioral issues. ${ }^{3,4}$ In addition, the association of microcephaly with aortic atresia and delayed brain maturation in patients with CHD compared with control neonates provide additional support to the notion that prenatal injury might be a significant contributor to the neurodevelopmental sequelae that affect some children with CHD. ${ }^{5}$

In light of this compelling evidence, the logical approach would seem to be to study a variety of factors that might

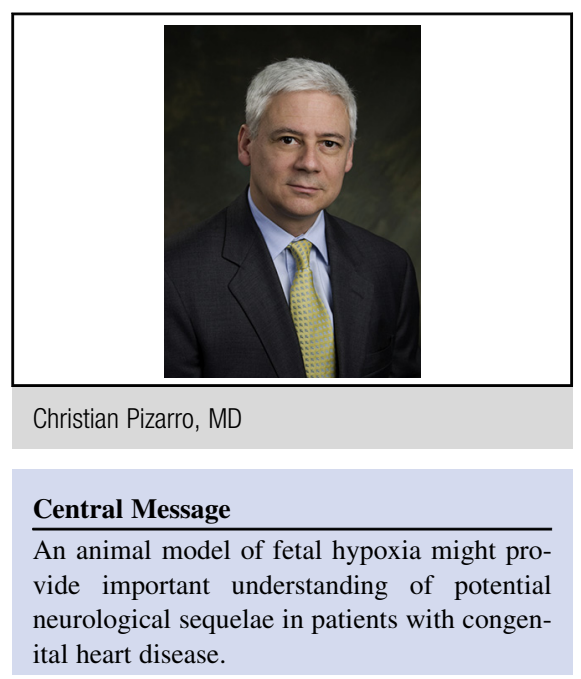

See Article page 270.

influence brain development in utero. The work presented by Lawrence and colleagues ${ }^{6}$ in this issue of The Journal of Thoracic and Cardiovascular Surgery represents an important initial step in that direction. The availability of a fetal model provides a unique opportunity to study the effect that abnormal circulatory patterns and ultimately decreased oxygen delivery might have in the developing brain, on different cell lines and perhaps create an opportunity to study strategies to ameliorate or eliminate some of the debilitating neurobehavioral sequelae that continue to affect some of these patients. It is entirely possible that this work might be the key to amplify our understanding and define best practices to achieve the best functional outcome for our patients.

\section{References}

1. Newburger JW, Jonas RA, Wernovsky G, Wypij D, Hickey PR, Kuban KC, et al. A comparison of the perioperative neurologic effects of hypothermic circulatory arrest versus low-flow cardiopulmonary bypass in infant heart surgery. $N$ Engl J Med. 1993;329:1057-64.

2. Bellinger DC, Wypij D, duplessis AJ, Rappaport LA, Jonas RA, Wernovsky G, et al. Neurodevelopmental status at eight years in children with d-transposition of the great arteries: the Boston circulatory arrest trial. J Thorac Cardiovasc Surg. 2003; 126:1385-96.

3. Miller SP, McQuillen PS, Vigneron DB, Glidden DV, Barkovich AJ, Ferriero DM, et al. Preoperative brain injury in newborns with transposition of the great arteries. Ann Thorac Surg. 2004;77:1698-706.

4. Mahle WT, Tavani F, Zimmerman RA, Nicolson SC, Galli KK, Gaynor JW, et al. An MRI study of neurological injury before and after congenital heart surgery. Circulation. 2002;106(suppl I):I-109-14. 
5. Licht DJ, Shera DM, Clancy RR, Wernovsky G, Montenegro LM, Nicolson SC, et al. Brain maturation is delayed in infants with complex congenital heart defects. J Thorac Cardiovasc Surg. 2009;137:529-36.
6. Lawrence KM, McGovern PE, Mejaddam A, Rossidis AC, Baumgarten H, Kim AG, et al. Prenatal hypoxemia alters microglial morphology in fetal sheep. J Thorac Cardiovasc Surg. 2020;159:270-7. 